\title{
O romantismo paulista (os ensaios literários e o periodismo acadêmico de 1833 a 1860), de Hélder Garmes
}

\author{
Cillaine Alves Cunha ${ }^{1}$ \\ Universidade de São Paulo
}

rincipal veículo de circulação das propostas de renovação e nacionalização da literatura, o periodismo científico e literário do século XIX perpetua-se, nos dias atuais, ou por meio de fac-símiles, ou na forma de antologia - como no indispensável Textos que interessam à história do romantismo, organizado por José Aderaldo Castelo -, ou, ainda, nas raras pesquisas sobre o tema. Entre os títulos que dele tratam, $A$ divisão das águas, de Hélio Lopes, analisa as revistas Minerva brasiliense (1843-1845) e Guanabara (1849-1856), que disseminaram as novas idéias de definição do indianismo, casadas com o entusiasmo diante da modernização do país.

O recente lançamento de O romantismo paulista (os ensaios literários e o periodismo acadêmico de 1833 a 1860), de Hélder Garmes, dedica-se, por sua vez, ao estudo das publicações representativas de outra vertente do romantismo brasileiro, concomitante ao indianismo e equivocadamente denominada "subjetivista" ou "egotista". Trata-se das revistas editadas entre os anos de 1830 e 1860 por associações de estudantes da faculdade do Largo de São Francisco, material que, além de não ter merecido edições atualizadas, não havia ainda sido estudado. Entre elas, o livro privilegia a coleção de exemplares da revista multidisciplinar Ensaios literários (1847-1850), confeccionada pelo Instituto Literário Acadêmico, associação criada pelos primeiranistas da turma de 1846. O instituto e sua revista contaram, entre seus fundadores

\footnotetext{
${ }^{1}$ Cilaine Alves Cunha é professora doutora de Literatura Brasileira pela USP e autora de O Belo e o Disforme: Álvares de Azevedo e a ironia romântica. São Paulo: Edusp/Fapesp, 1998.
} 
mais célebres, com José de Alencar e, entre os colaboradores, com Álvares de Azevedo, Andrada e Silva, Bernardo Guimarães, etc.

Para definir o lugar da Ensaios literários no interior do publicismo e do associativismo romântico, Garmes recupera a sua história, comparando o seu objeto com outras publicações do tempo. As edições acadêmicas do período remontariam, para ele, à efêmera Revista da Sociedade Filomática (jun./ dez., 1833), quando a prática associativa foi abandonada por longos anos. No final de 1840, a retomada dessa experiência resultou em três distintas revistas. Além da Ensaios literários, o período contou, entre outras, com a Revista mensal do ensaio filosófico paulistano (1851-1864) e com a Ensaios literários do Ateneu Paulistano (1851-1866). O termo "ensaio", comum a esses três periódicos, não evidencia, como esclarece Garmes, princípio algum de continuidade entre eles. Ao preservarem o nome de sua antecessora, as duas últimas revistas procuram construir uma tradição e sugerir um valor histórico para essa "espécie de família", esperando, com isso, granjear para si a memória e o êxito editorial da Ensaios literários.

Na compreensão de Hélder Garmes, a Filomática serviu de modelo a um tipo de associação científica e literária que se imbuiu da iluminista convicção de que o movimento e a troca de idéias poderiam estimular o cultivo da razão, o desenvolvimento do progresso e o encaminhamento da nação rumo à civilização. Entre os estudantes da década de 1850, a experiência agremiativa alternou as aulas do curso de direito com reuniões de discussão intelectual. Em conseqüência, a convivência simultânea de estudos jurídicos e humanísticos com debates sobre ciência e literatura favoreceu a criação de um espaço de treinamento na carreira jurídica, antecipando, de certa forma, o exercício legislativo. Mas foi também terreno fértil para a fundação de uma espécie virtual de "academia de belas letras". Enfim, essas agremiações funcionaram como um clube de escolhidos, que, logo em seguida, se projetaram na carreira de bacharel e na literária, habilitandoos e legitimando-os para a ocupação dos cargos públicos.

Em 1833, a suspensão das associações coincidiu com o conturbado período das revoluções regenciais, quando a elite brasileira se debatia entre si, dividida entre os mais diversos interesses políticos e econômicos. Em contrapartida, por volta do final de 1847, a iminência do controle das revoluções pelo governo monárquico abriu um novo período na história do Império. A partir de então, a Monarquia começa a construir os parâmetros ide- 
ológicos que lhe permitirão unificar a elite brasileira em torno de seu projeto conservador, formando a base política que, daí a pouco com a Conciliação (1853), lhe dará sustentação ao longo de sua existência. Visto nesse decisivo momento, o apoio às agremiações de estudantes, prestado por um dos principais centros intelectuais de sustentação do governo imperial, o Instituto Histórico e Geográfico Brasileiro (IHGB), evidencia as primeiras tentativas da elite intelectual de controlar a cultura do país e, com isso, produzir sua hegemonia ideológica.

Assim, nos capítulos dedicados à análise interna da Ensaios literários, Hélder Garmes aborda os temas e os gêneros aí predominantes, seu público-alvo, seu projeto de nação com sua correspondente concepção de literatura, levantando os pontos de contato entre o seu projeto editorial e o da Revista do IHGB. Entre essas coincidências, ressalta-se a glorificação da figura do bacharel, fartamente louvado também na prosa canhestra de Gonçalves de Magalhães, figurando, ainda, em muitas poesias de Gonçalves Dias. Autonomeando-se portador das luzes, o bacharel se autoconstitui como um profeta que, reconhecendo o alto índice de analfabetismo no país, concebe a entidade "povo" como uma virtualidade, produzindo uma recepção pragmática cujo público privilegiado é a própria corporação. Boa parcela desses intelectuais reunidos em torno da Ensaios literários define seu lugar intermediário entre o Estado e esse suposto "povo". Mas, enquanto se lêem uns aos outros, eles disseminam um núcleo ideológico comum que tende a favorecer certa unificação e reconhecimento dessa corporação na vida política e social. Mas a revista tampouco deixa de oferecer argumentos para um discurso que aplaque os pontos mais nevrálgicos da política imperial.

Entre os autores prediletos da corporação, o socialismo católico de Lamennais impõe-se como uma referência, mas não sem que se aplaine sua reação panfletária contra a monarquia e as formas de escravidão, seja ela a primitiva, seja a formal. Procurando reforçar o catolicismo como religião oficial do país, a Ensaios literários universaliza-o num suposto pendor natural do brasileiro à crença e ao misticismo. Num voraz espírito eclético que tudo incorpora e deglute, típico da elite no capitalismo, postula que o catolicismo seria a única religião capaz de harmonizar-se com a razão. Como resultado desse caldo de cultura, a disseminação de um romantismo de consolação, promotor de um discurso em favor da tolerância e da resignação, tende a produzir 
as mais variadas contradições ideológicas, que, no entanto, podem esvaziar o clima revolucionário que então assombrava o país. Os autores da revista reivindicam ainda um governo justo e soberano, mas sem questionar a legitimidade nem da monarquia, nem da escravidão. Não apenas nesse periódico, mas em toda a vertente mais conservadora do romantismo brasileiro a tendência foi afirmar que as iniqüidades políticas e sociais da época poderiam ser minoradas caso a elite escravocrata adotasse um sentimento de generosidade e de caridade para com os excluídos, especialmente os escravos.

Em que pese, no entanto, o esforço de unificação do discurso político e literário, um traço característico do associativismo estudantil, ressaltado de diversas formas em $O$ romantismo paulista, é a pluralidade e o antagonismo das posições políticas e estéticas. Seja devido à própria irreverência que tende a caracterizar a vida estudantil, seja ainda pelo fato de que o romantismo praticado pelos estudantes incorporou com maior fidelidade o preceito romântico de valorização da contradição e do sentimento dos contrários, a revista e o ambiente na faculdade oitocentista primaram pelo exercício da oposição crítica.

Nesse sentido, o livro procura recuperar as discussões sobre a renovação da literatura e o modo de implantar o romantismo no Brasil, analisando quatro artigos nos quais se ressaltam a diversidade de opinião e as divergências sobre o assunto: de Almeida Pereira, "Breves considerações sobre o romance" (1847); de Bernardo Guimarães, "Reflexões sobre a poesia brasileira" (1847-1850, único texto reproduzido integralmente por Garmes); de José de Alencar, "O estilo na literatura brasileira" (1850, reproduzido por Valéria de Marco em O império da cortesã); e de Álvares de Azevedo, "Alfred de Musset, Jacques Rolla" (1850, incorporado a edições de suas obras completas).

Almeida Pereira silencia-se quanto à nacionalidade em literatura, priorizando propostas de renovação da forma literária, que, diversificada nos subgêneros do romance (político, social, histórico e filosófico), deveria adaptar a linguagem artística ao prosaísmo. Bernardo Guimarães recusa-se, por sua vez, a admitir que o Brasil possuía uma literatura própria, apresentando, para tanto, um conjunto de propostas que, avessas à unificação da cultura local por meio de uma suposta "essência" projetada no indígena, valorizam a incorporação da heterogeneidade cultural inscrita nas diversas regiões e camadas sociais do país. Já o jovem José de Alencar aproxima-se de Almeida Garrett ao propor a nacionalização da literatura por meio de uma flexibilização do quinhentismo 
português, casada com a apropriação de termos emprestados do vocabulário indígena. Espera, com isso, conquistar uma linguagem literária "simples", "humilde", "nobre" e "majestosa", supostamente próxima da linguagem popular, tal como já estava fazendo Gonçalves Dias. Ignorando, como os dois primeiros articulistas, a unidade da literatura pelo nacional, Azevedo procura destacar seu intuito de desestabilizar a autoridade da tradição, mediante um diálogo e uma revisão crítica dos clássicos.

O espírito de contradição que marca o romantismo estudantil fica ainda evidente nas duas posições poéticas antagônicas que aí se digladiam. Esse antagonismo organizou-se, conforme Garmes, em torno do par crença/descrença, respectivamente personificado nos poetas Lamartine e Victor Hugo, de um lado, e Byron, de outro. O ponto de discórdia entre essas tendências funda-se numa postura ou de afirmação ou de negação do progresso e do sentimento de nação. Derivado da polêmica, o número significativo de poesias, reproduzido na Ensaios literários, que cantam a desilusão amorosa surge como uma reação ao privilégio que então se concedia ao sublime divino, personificado na figura da virgem.

Ao destacar as divergentes opiniões sobre a teoria e a prática poética dos românticos, O romantismo paulista amplia o arco com que muito comodamente se costuma definir esse movimento no Brasil, em geral fragmentado em vários períodos e com a ênfase canônica concedida ao indianismo. Ao apresentar uma outra face dessa moeda, com suas complexas questões e gêneros inesperados, o livro de Hélder Garmes realiza um deslocamento dos clichês e equívocos que a crítica literária vem produzindo sobre essa estética, o que estimula o revigoramento dos estudos sobre o romantismo no Brasil.

\section{Referências Bibliográficas}

AZEVEDO, Álvares. Obras completas. Org. Homero Pires. Rio de Janeiro: Cia. Editora Nacional, 1942.

GARMES, Hélder. O romantismo paulista: os ensaios literários e o periodismo acadêmico de 1833 a 1860. São Paulo: Alameda, 2006.

MARCO, Valéria de. O império da cortesã. Lucíola: um perfil de Alencar. São Paulo: Martins Fontes, 1986. 
